Reflecting on the world as a text poses a good number of questions on language. M. Carmen Africa Vidal then turns to the issue of creating a text: the role of the author, his/her dissolution in the ocean of repetitions and references that shape contemporary fiction, its ultimate expression being the computer-assisted hypertext. Originality, identity, the historical subject may all lose their meaning, or at least alter it substantially. Yet it is a characteristic of contemporary culture that there is no single, closed text. Narrative texts elude a linear sequence, and their author appears disseminated, disintegrated in a plurality of textual layers, most of which cannot be clearly assigned to a single, masterful subject. A paradoxical situation is revealed: despite its welcome tendency towards pluralism and the acceptance of the Other, the so-called death of the author may carry with it a tendentious homogenization, a "renaissance of the Same," to the disadvantage of distinct cultural identities. $\mathbf{M}^{\mathbf{a}}$ Carmen África Vidal warns against this and many other dangers of postmodern thought inadequately understood. The politics of language points towards the anomalous domain of power: as relevant as what is being said are those blank spaces that remain unuttered, those skipped meanings, the play on words, those imprecise garments that eventually become "the only way to gain access to the realm of ethics."

The last chapter displays the cultural paradoxes of these anxious times, drawing upon instances of popular and high culture, always interrelated. Cultural icons such as Madonna and relevant theorists such as the post-marxist critic Jameson, among many others, are the objects of a serious reflection on the fin-de-siecle cultural hotchpotch. Fashion, sex and love are some of the aspects examined, models of a contemporary society obsessed with nostalgia and simulacra.

In short, this perspicacious book, written in an at times cynical, but always concerned Borgesian style, offers an enjoyable and assertive insight into the predicament of culture studies. It may help us not to waste "the postmodern occasion," as it has been termed, but, above all, through post-technological icons and signifiers, it will surely give us matter for reflection and perhaps a new attitude towards life and books, the immense library of everyday experience.

Ovidio Carbonell

\title{
Walt Whitman. Hojas de hierba: antología bilingüe. Trans. and notes Manuel Villar Raso. Madrid: Alianza Editorial, 1995, 276 pp.
}

In a brief review like this one, very little that is new can be said about Leaves of Grass, one of the most frequently discussed works in the English language and one which has already been translated several times into Spanish by poets and writers as famous as José Martí or Jorge Luis Borges. It therefore seems more advisable to focus on the values and intentions of the translation, and to abstain from reassessing the main traits of a book written by Whitman in 1855 and revised by him time and again.

Translation is characterized by what might be termed a double tension between the reproduction of the source text and the creation of a new text which seeks to attain a degree of efficiency and quality dictated by the target system conventions. In this 
connection, in translation studies a now traditional distinction is drawn between the translation of poetry and poetic translation. The former defines a target text which does not aspire to appear as a poem in its own right within the target system, but as a good reproduction of the semantic material included in the source text. Poetic translation, on the other hand, accords the aesthetic objectives, as they are established within the target culture, at least the same importance usually granted to the semantic material of the source text. Thus, this type of translation is ready to give up the contents (at least partially) in exchange for formal excellence. In spite of past controversies which have long raged the literature on translation, currently there seems to be a general agreement as to the idea that the quality and, of course, the legitimacy of the two types are not subjects on which $a$ priori judgements can be founded, since each performs a different function and it is the purpose of a given translation (the scopos, to use a very much quoted term) which tips the scales in favour of either option.

Bilingual editions like the one analysed here obviously tend towards the "translation of poetry" option. Since they are intended for readers posessing a reasonable mastery of the source language, the presence of the original as it was written by its author allows them access to its formal virtues, while, at the same time, they can also turn to the translation for help with at least their more superficial problems of comprehension. Thus, when a translation is designed to be included in a bilingual edition, it does not usually aim to replace the original (the function, par excellence, of poetic translations), but to accompany it by providing support for a reader who does not have complete mastery of the source language. This seems to be the main function all through this anthology of Leaves of Grass, translated and annotated by Manuel Villar Raso, since he keeps as close to the source text as possible, offering the classic structure in which the translation matches the original line by line or with a minimum carry-over to the next line. The reader is thus enabled to focus on the English version and, at a glance, clear up any doubt he may have as to the sense of the words or phrases of the source text. The translator will offer him exactly that in a version which marries correctness in the use of Spanish with the closest approximation to the source text. Villar Raso's version succeeds in this aim, and even provides a series of footnotes, usually to explain cultural and geographical references in which the mere transference of the semantic material could not suffice. This last feature further confirms the auxiliary nature of this translation in line with its being issued in a bilingual edition. The intention behind the translation can easily be appreciated through a quick comparison between this version and that by Borges, probably the best known in Spanish. Though the anthology selected by Borges is based on a different source text and many of the poems chosen are not to be found in Villar Raso's translation, if we compare for instance the two versions of "Song of Myself" it is clear that the one written by Borges is intended as a replacement for the original and, in consequence, aims to stand as an autonomous poem of high quality, even if this means some degree of conscious deviation from the original.

Another important feature of Villar Raso's version is the fact that it is a retranslation. Usually, when there has been no important change in the literary conventions of the target system, retranslations tend to be, with the occasional exception of theatre translations, more and more oriented towards the reproduction of the original. This is possibly due to 
the fact that the only works that are retranslated are those which have entered the canon in the new system, and this new status gives the translator greater leeway with the specific conventions of the target literary system in a situation in which the nature of the recognized "work of art" acquires greater importance. In fact, on the back cover there is a statement which expands on something said by the translator in his introduction: "The novelty and interest of this BILINGUAL ANTHOLOGY ... rests on the fact that for the first time we are offered a Spanish translation of Whitman's poems in their first versions, in which the urge that brought them into being manifests itself much more faithfully than do the final ones, expurgated by the poet himself." Thus, the idea of "fidelity" prevails in the translator's intention to such an extent that, in a very unusual but significant move, it is claimed that the source text chosen in this case is the most faithful to the "spirit" of the writer-curiously enough, actually against his will, because Whitman asked to be published always in the last version to be revised by himself, i.e. what is commonly known as the deathbed edition. The claim that this edition is the most faithful is also extremely revealing as to the prerogatives of every translation, which in the act of interpretation establishes its own source text. In this case, the situation is made much clearer by the two facts that the translator has had to choose among several possible source texts, and that he has sifted even that version and kept only a part of itpressumably what he sees as the most genuine part.

In short, we have here a new Spanish version of Leaves of Grass whose main innovation lies in the fact that it presents the poems in a version, the first one, scarcely known in the English-speaking countries and completely unknown in the Spanish literary system. This is, undoubtedly, a new contribution that should be welcomed. From a stylistic point of view, Villar Raso's translation is what has been termed a translation of poetry, i.e. an auxiliary version. Its formal ambitions are therefore limited, though it shows a clear concern for correctness and it pays special attention to linguistic tenor, much in line with this type of translations, which on the semantic level stay very close to the original at the same time as they respect target language usage.

Javier Franco Aixelá

William Shakespeare. Titus Andronicus. Ed. Jonathan Bate. The Third Edition of the Arden Shakespeare. London: Routledge, 1995 - William Shakespeare. Antony and Cleopatra. Ed. John Wilders. The Third Edition of the Arden Shakespeare. London: Routledge, 1995 - William Shakespeare. King Henry V. Ed. T. W. Craik. The Third Edition of the Arden Shakespeare. London: Routledge, 1995.

We welcome the publication of Titus Andronicus (edited by Jonathan Bate), Antony and Cleopatra (edited by John Wilders) and King Henry V (edited by T. W. Craik), the first three plays to appear in the third edition with a new concept of editorial work. The Arden Shakespeare has been a landmark in textual analysis and critical research for nearly one hundred years. It has been the origin of a textual revolution in the editing of Shakespeare plays and has been particularly productive in the last decades of this century. The new 